\title{
Microbially-mediated formation of manganese carbonates hosted in Cryogenian black shales in South \\ China
}

JIAYI AI ${ }^{12 *}$, SANDRA SILJESTRÖM ${ }^{3}$, NINGNING ZHONG ${ }^{1}$, SiMON C. GEORGE ${ }^{2}$ AND LIJUAN HUANG ${ }^{1}$

${ }^{1}$ State Key Laboratory of Petroleum Resources and Prospecting, College of Geosciences, China University of Petroleum-Beijing, Beijing, 102249, China

(*correspondence: jiayi.ai@hdr.mq.edu.au)

${ }^{2}$ Department of Earth and Environmental Sciences, Macquarie University, Sydney, NSW 2109, Australia

${ }^{3}$ RISE Research Institutes of Sweden, Borås, 50115, Sweden (sandra.siljestrom@ri.se)

The manganese (Mn) deposits in the Datangpo Formation in South China were formed during the interglacial stage between the Sturtian and Marinoan. These black shales host Mn deposits that dominantly occur as rhodochrosite and Carhodochrosite, minerals that are typically interpreted to form through physiochemical processes. In this study, systematic petrographical and geochemical analyses suggest microbiallymediated processes have regulated the precipitation of the Mn carbonates, which have a radial-concentric microfabric (i.e. ooidal) texture with a particular organic-ring layer.

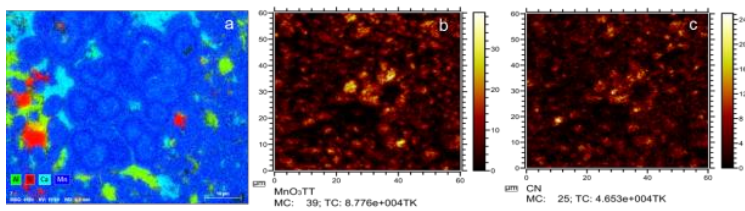

Figure 1 Combined elemental mapping (Al, Si, Ca and $\mathrm{Mn}$ ) and ToF-SIMS figures of the Mn carbonates.

Hydrothermal-derived $\mathrm{Mn}(\mathrm{II})$ was oxidised to $\mathrm{Mn}$ oxides/hydroxides through catalytic reactions associated with bacteria (e.g. Mn-oxidising bacteria) under relatively low atmospheric-ocean $\mathrm{O}_{2}$ levels. Extracellular polymeric substances, which were likely produced by cyanobacteria, could have served as nucleation sites and as a potential carbon source during heterotrophic microbially-mediated $\mathrm{Mn}$ reduction within the organic-rich sediments. A contribution of dissolved inorganic carbon derived from oxidised organic matter (OM) is supported by the light $\delta^{13} \mathrm{C}_{\text {carb }}$ compositions (6.6 to $-9.6 \%$, average $=-8.4 \%$ ) and the ToF-SIMS data (Figure 1), which exhibit close localisation of the Mn within the $\mathrm{OM}\left(\mathrm{CN}^{-}\right)$enriched phases. Thus, microbially-mediated Mn-carbonate formation in the DTP-1 is inferred to have been an essential process for both the $\mathrm{Mn}$ and the carbon cycle during the Cryogenian interglacial period. 